\title{
The Effects of Knowledge Assets on the Performances of Startup Firms: Moderating Effects of Promotion Focus
}

\author{
Sang Yun Seo ${ }^{1}$, Sang Duck Kim², Myoung-Soung Lee ${ }^{3}$ \\ Received : September 152018 Revised: October 21, 2018 Accepted: October 10, 2018
}

\begin{abstract}
This study examined the effects of startup firm's knowledge assets on the effectiveness of their sales strategies, efficiency of sales activities, and management performance, after categorizing these assets into customer knowledge assets and technology knowledge assets. Furthermore, the moderating effects of promotion focus by CEOs and sales managers of startup firms were analyzed. For the analysis, dyadic questionnaire surveys were conducted targeting the CEOs and sales managers of startup firms established at the Gyeongnam Technopark and the KAIST Technology Business Incubation Center in Korea. Hypotheses were verified through structural equation modeling, and moderating effects were identified through ANOVA. CEO's customer knowledge asset strengthened their effectiveness of sales strategies, and sales manager's technology knowledge asset strengthened the efficiency of their sales activities. Also, CEO's effectiveness of sales strategies and sales manager's efficiency of sales activities have been found to enhance startup firm's management performance. Meanwhile, the moderating effect of promotion focus strengthened CEO's effectiveness of sales strategies through CEO's customer knowledge asset and interaction as CEO's promotion focus level increased, but promotion focus of sales managers did not have any significant interaction effect. This study provides implications by offering empirical evidence on startup firms with regard to knowledge assets.
\end{abstract}

Keywords: Knowledge Assets, Effectiveness, Efficiency, Promotion Focus, Startup Firm.

JEL Classifications Code: L10, M10, M31.

\section{Introduction}

Today's enterprises identify ways of utilizing knowledge assets to successfully implement transformations and innovative activities for business, environmental, and social growth (Lopes, Scavarda, Hofmeister, Thomé, \& Vaccaro, 2017). Firms accomplish sustainable goals through the acquisition and management of knowledge regarding customers and other environments (Kaiser, Köhler, \& Weith, 2016; Sujatha \& Krishnaveni, 2015). Hence, several previous studies perceive the activities of obtaining and managing knowledge assets as playing a critical business

1 First Author, Assistant Professor, Department of Business Administration, Kyungnam University, South Korea.

E-mail: syseo@kyungnam.ac.kr

2 Professor, Department of Business Administration, Kyungnam University, South Korea.

3 Corresponding Author, Associate Research Fellow, Incheon Foundation for Women and Family, South Korea,

E-mail: sambaq2000@naver.com role and emphasize them as key factors in corporate competitiveness (Cerchione \& Esposito, 2017). In particular, the activities of acquiring and utilizing knowledge assets are crucial for a startup's business. Startup firms are organizations that explore and organize sustainable and expandable business models, while severely lacking resources in comparison with other companies (Blank \& Dorf, 2012). Thus, they are highly dependent on intangible assets such as knowledge for business sustainability. However, most studies on knowledge assets are conducted on large enterprises and small and medium-sized firms, and a concrete and empirical approach is lacking with regard to startup firms (Centobelli, Cerchione, \& Esposito, 2017). Furthermore, studies on knowledge assets of startup firms identify the antecedent factors influencing knowledge assets (Mathew, Rodrigues, \& Vittaleswar, 2012) or focus on the performance of knowledge management systems (Wang \& Yang, 2016). Since startup firms lack sufficient financial resources, they seek investment and profits to sustain business activities. Investment is decided based on corporate profitability, and profits are shown based on sales 
results. In that sense, sales activities are a central part of startup firm's business activities. Since knowledge assets are perceived as a strategic factor in corporate management (Spender, 1996), they are expected to play an instrumental role in sales by startup firms. However, previous studies have not academically discussed the roles of knowledge assets with regard to sales by startup firms.

This study identified the roles of knowledge assets with regard to sales by startup firms. Normally, since startup firms launch businesses based on innovative technology or ideas, CEOs come to possess professional knowledge regarding technology but have relatively little knowledge regarding customer needs or market information. If CEOs possess knowledge assets regarding customers, they can establish effective sales strategies by understanding appropriate customer groups and applying effective sales ideas (Pollard \& Jemicz, 2006). Conversely, since the sales manager's key role is interacting with customers (Bitner, Booms, \& Mohr, 1994), their customer knowledge is high but expert knowledge with regard to technology is relatively lower. Sales managers come into contact with customers through products. In that sense, when the sales manager's knowledge regarding product-related technology is high, sales activities can be performed efficiently (Zablah, Chonko, Bettencourt, Allen, \& Haas, 2012). Thus, sales manager's knowledge assets regarding technology can be positively applied in sales activities. In this aspect, this study aimed to identify the effects of cross-functional knowledge assets by CEOs and sales managers with regard to customers and technology on sales strategies and sales activities.

Meanwhile, previous studies have identified that outcomes differed based on personal motivational characteristics under the same circumstances (Higgins, 1989, 1997). Of the diverse discussions on motivational characteristics, regulatory focus is drawing the greatest attention. Regulatory focus theory explains the process of how individuals lead themselves based on their own standards and goals and engage in selfregulation (Brockner, Higgins, \& Low, 2004). According to the theory, CEOs and sales managers of startup firms make decisions by being involved in either promotion focus or prevention focus and special outcomes emerge through interaction with other factors (Higgins, 2000). Thus, this study aimed to identify the moderating effects of regulatory focus between knowledge assets by CEOs and sales managers regarding customers and technology and the factors related to sales. In particular, this study focused on promotion focus because it is of greater importance in the pursuit of profits in terms of growth and development than prevention focus, which aims to avoid potential losses, since startup firms have an entrepreneurial characteristic of generating products or ideas that have successful potential (Brockner et al., 2004).
In summary, this study tried to examine the effects of startup firm's knowledge assets on sales and performance and identify the moderating effects of promotion focus. In detail, this study aims to identify the effects of CEO's customer knowledge asset on startup firm's management performance through CEO's effectiveness of sales strategies. Moreover, this study aims to understand the effects of sales manager's technology knowledge asset on startup firm's management performance through sales manager's efficiency of sales activities. Lastly, this study tries to examine the moderating effects of promotion focus between knowledge assets and factors related to sales. It seeks to explore knowledge assets by focusing on startup firms. In particular, it offers empirical evidence with regard to the roles of knowledge assets in the sales domain, which have not been examined so far.

\section{Theoretical Background}

\subsection{Knowledge Assets}

Knowledge assets refer to the degree to which individuals accumulate and utilize knowledge. In terms of enterprises, knowledge assets can be defined as the knowledge accumulated with regard to items, market, technology, process, and organization demanded by companies, or which generates profits. Knowledge assets are not only a key factor influencing financial outcomes of enterprises (Wang, Zhao, \& Chen, 2017) but also become significant resources for forming competitiveness (Centobelli et al., 2017). Also, knowledge assets do not reduce in value; thus, they are not depleted since they can be essentially reproduced. Furthermore, knowledge assets become more valuable with increased usage. Most assets possessed by firms have the potential to decrease profits, but this is not the case with knowledge (Apostolou, Mentzas, Abecker, Maas, Georgolios, \& Kafentzis, 2005). In this sense, knowledge is a key asset for startup firms, which have scarce resources compared to competitors. Knowledge assets encompass the technology that enables interaction between human capital and knowledge (van der Wal, 2017). Thus, knowledge assets are acquired and developed at the individual level and expanded at the organization level. Key members of enterprises (e.g., CEO and sales manager) can enhance the performance of startup firms by obtaining specific knowledge related to the firm and developing it (Wang, Zhao, \& Chen, 2017).

\subsection{Effectiveness and Efficiency}

Effectiveness and efficiency are key terms used in measuring and evaluating performance (Mouzas, 2006). Moreover, the two terms apply both at the individual and 
organizational levels. Effectiveness is based on the idea that the measures to accomplish goals should be considered in decision-making, and it is related to the efforts or activities to accomplish goals. Thus, this is more focused on the activities designed for performance improvement (Clark, 2000). In this sense, Walker and Ruekert (1987) connected effectiveness to activities for greater success than the competition. In addition, Pérez-Nordtvedt, Kedia, Datta, and Rasheed (2008) defined effectiveness as usefulness in terms of significance to success. Efficiency refers to the comparison of returns on investment of resources and aims to maximize the returns (Bonoma, 1988). In terms of efficiency, also known as productivity, it means selecting one alternative generating greater performance among several alternatives of investing the same amount of resources or selecting one that consumes the least amount of resources out of several alternatives generating the same performance (Simon, 1965). In that sense, Pérez-Nordtvedt et al. (2008) defined efficiency as speed and economic feasibility. In a similar sense, Walker and Ruekert (1987) suggested business results such as return on investment (ROI) as one measure to identify efficiency. When the characteristics of the two concepts are examined based on the aforementioned discussion, effectiveness encompasses output-oriented perspectives and generation of customer values whereas efficiency involves utilization of resources and input-oriented perspective. According to these perspectives, Grönroos and Ojasalo (2004) defined effectiveness as an external aspect (profit-making ability) and efficiency as an internal aspect (efficient use of resources and expenses).

Since previous studies distinguished effectiveness and efficiency as two distinct concepts, this study separated effectiveness and efficiency. Particularly, effectiveness was connected to sales strategies and efficiency was linked to sales activity since strategic purpose implies responding to the external environment (Lee \& Griffith, 2004), and activities have to do with maximizing the accomplishment of activity goals by utilizing distributed resources.

Table 1: Comparison between effectiveness and efficiency

\begin{tabular}{|c|c|c|}
\hline $\begin{array}{c}\text { Central } \\
\text { meaning }\end{array}$ & $\begin{array}{c}\text { Efforts or activities } \\
\text { to accomplish goals }\end{array}$ & $\begin{array}{c}\text { Comparison between } \\
\text { invested resources and } \\
\text { results }\end{array}$ \\
\hline Similar concept & Usefulness & Productivity \\
\hline Perspective & Output oriented & Input oriented \\
\hline $\begin{array}{c}\text { Dimension of } \\
\text { relevant business } \\
\text { capability }\end{array}$ & $\begin{array}{c}\text { External aspect } \\
\text { (profit-making ability) }\end{array}$ & $\begin{array}{c}\text { Internal aspect } \\
\text { (efficient use of resources } \\
\text { and expenses) }\end{array}$ \\
\hline
\end{tabular}

\subsection{Promotion Focus}

Regulatory focus, which was systematized by Higgins (1997), argues that human motivation can be divided into the motive to approach pleasure and the motive to avoid pain. The motive to approach desire is promotion focus and the motive to avoid pain is prevention focus. Promotion focus is interested in whether positive results exist or not and uses behavioral strategies to approach them; it experiences pleasure when encountering positive outcomes and experiences disappointment when unable to encounter positive results (Lee, 2017; Lee, Oh, \& Kim, 2014; Park \& Lee, 2016). Conversely, prevention focus is interested in whether negative results exist or not and uses behavioral strategies to avoid them; it experiences anxiety when encountering negative outcomes and experiences relief when not encountering negative outcomes (Higgins, 2000). Regulatory focus exists in all human beings, but a certain side can appear much stronger based on the environment and experiences during the period of growth (Yoo \& Hyun, 2011). Moreover, even in the case of individuals with a certain stronger tendency, it may appear differently according to certain situations and regulatory focus, which has greater influence based on individual characteristics, may exist (Higgins, 2000).

Regulatory focus can appear between managers and employees within organization. While promotion focus concentrates on accomplishments of employees, prevention focus aims for fulfillment of given duties and safety. Accordingly, managers can emphasize either a promotion or prevention focus vis-a-vis employees (Higgins, 1989). Employees with promotion focus experience pleasure when managers offer compensation while complimenting their creativity or encouragement to pursue new opportunities. However, when managers stop complimenting and become indifferent to their accomplishments, they experience pain. Conversely, employees with prevention focus experience pleasure when managers train them to not commit potential dangers or wrongful acts. However, when managers punish them for being irresponsible or careless, they feel pain.

Of the aforementioned regulatory focuses, this study is interested in promotion focus. Large enterprises with wellestablished management systems need both promotion focus, which is creative and pursues higher performance, and prevention focus, which accomplishes duties and strives not to fail. Promotion focus has greater importance for startup firms, which have relatively underdeveloped management systems, are creative, and need an active working style (Henker, Sonnentag, \& Unger, 2015) since entrepreneurship, a requirement for startup firms, has a lot to do with promotion focus (Brockner et al., 2004). 


\section{Hypotheses Development}

\subsection{CEO's Customer Knowledge Asset and CEO's Effectiveness of Sales Strategies}

Strategy is the process of planning goals and implementing them in an appropriate manner. It encompasses sales objectives and budgets, schedule setting, major sales stages, and performance management (Tiwana, 2009). Thus, appropriateness of goal setting, organization of realistic sales plans and plausible schedule setting, and access to vast resources improve the effectiveness of sales strategies. In a bid to improve effectiveness of sales strategies, knowledge regarding customers is necessary. Startup firms can discover sales possibilities and limiting factors after deriving customer characteristics through knowledge regarding customers. Firms can set realistic sales objectives and enable adequate resource allotment. Furthermore, since sales target customers, sales strategies are revised based on the location where startup firms have an established status and how effectiveness is decided (Thomas, Ambrosini, \& Hughes, 2017). Therefore, to establish effective sales strategies, extensive and detailed customer information is needed. Since startup firm's strategies are established and revised by CEOs who are the decision-makers (Wadhwa, McCormick, \& Musteen, 2017), previous studies emphasized CEO's knowledge regarding markets and customers as the key factors in effectively implementing sales strategies (Atuahene-Gima \& Murray, 2004; Fidel, Schlesinger, \& Cervera, 2015). These discussions show that effectiveness of sales strategies can be improved by CEO's customer knowledge asset. Thus, the following hypothesis has been proposed.

H1: CEO's customer knowledge asset has a positive influence on the CEO's effectiveness of sales strategies.

\subsection{CEO's Effectiveness of Sales Strategies and Startup Firm's Management Performance}

Sales strategies are the response by startup firms toward competitive market environments (Lee \& Griffith, 2004) and involve establishing plans through decision-making and the process of implementing them (Han, 2016). Sales strategies and management performance of startup firms usually have strong relevance (Porter, 1980) since the firms establish sales strategies so as to improve product value and competitive advantage in response to external factors (Han, 2016). Previous studies have identified that sales strategies acted positively in such a context (Cavusgil \& Zou, 1994).
In order for startup firms to successfully implement sales strategies, it is necessary to align activities with organized sales strategies (Menon, Bharadwaj, Adidam, \& Edison, 1999). As the decision-making regarding sales strategies and their implementation work in the same direction, sales strategies are effectively conducted and achieve the desired outcome as correspondence increases, since customer needs are satisfied. This is because customers comprise the key external group that requires a response from companies, which must focus their internal capabilities to resolve customer problems. On the other hand, when correspondence is low, the outcome is inefficient solutions to customers' problems (Tiwana, 2009). Since the correspondence between sales strategies' decision-making and implementation activities determines usefulness of strategy goals, it refers to effectiveness of strategies. Thus, effectiveness of sales strategies is expected to directly influence corporate performance. In this sense, the following hypothesis can be set.

H2: CEO's effectiveness of sales strategies has a positive influence on startup firm's management performance.

\subsection{Sales Manager's Technology Knowledge Asset and Sales Manager's Efficiency of Sales Activities}

Normally, since most startup firms are based on new technology or ideas, expert knowledge is necessary so as to understand complex product-related technology. Purchasing products with high technological complexity can be perceived as a risk for customers (Homburg, Muller, \& Klarmann, 2011). When the technology of products is complex or expert knowledge with regard to technology is necessary, customers need more cognitive resources for purchase decisions (Thompson, Hamilton, \& Rust, 2005). Consequently, customers experience perceived risks regarding their purchases and their uncertainty increases. Customers aim to fulfill perceived resources by demanding knowledge with regard to technology in a bid to reduce such uncertainty (McQuiston, 1989). In this situation, the relational approach by sales managers toward sale can make sales difficult. Customers will perceive a sales strategy focusing on customer relations as an attempt to draw their focus away from technology and this reduces reliability of products. Reduced reliability on product technology generates more sensitive reactions since customers deliberate whether there are hidden or unperceived product-related aspects (Homburg et al., 2011). Since sales managers of startup firms perform sales activities with limited resources, it is important to accomplish 
sales objectives with the least amount of resources. Therefore, sales activities must be transformed flexibly based on the perceived information related to sales situations (Spiro \& Weitz, 1990). That is, to achieve sales of products, information on technology required by customers has to be determined and provided. Since customers desire innovative products, sales managers have to provide indepth knowledge regarding technology. Therefore, if sales managers have vast technology knowledge assets, their sales objectives are likely to be achieved in fewer sale attempts. Also, this signifies efficiency in sales activities. In this sense, the following hypothesis has been set.

H3: Sales manager's technology knowledge asset has a positive influence on the sales manager's efficiency of sales activities.

\subsection{Sales Manager's Efficiency of Sales Activities and Startup Firm's Management Performance}

Efficiency of sales activities refers to the accomplishment of sales objectives through sales activities conducted using the given financial and operational resources (AtuaheneGima \& Murray, 2004; Krohmer, Homburg, \& Workman, 2002). Efficient sales activities means achieving sales objectives with limited resources and for this, decisionmaking activities are conducted to suit sales situations (Bettman, 1988). Sales managers encounter customers with various sales situations and needs. Transforming sales methods to individual situations has a stronger effect on achievement of sales objectives than sales activities utilizing the same method (Spiro \& Weitz, 1990). Efficient sales activities are a positive factor in corporate performance. Customers have the tendency to regard sales manager's behavior as a reference criterion when assessing startup firms (Tortosa, Moliner, \& Sánchez, 2009). Thus, since sales activities responding to situations achieve not only relationship-building with customers but also sales objectives, it becomes a competitive advantage (Boles, Johnson, \& Barksdale, 2000). Moreover, sales are key to generating profits and pivotal for startups to deliver value to customers (Malshe \& Sohi, 2009). Since the number of successful sales increases when efficiency of sales activities rises, the delivery of corporate value increases and profits of startup firms increase. In this regard, performance of startup firms will improve. This results in the following hypothesis.

H4: sales manager's Efficiency of sales activities will positively influence the management performance of startup firms.

\subsection{Moderating Effects of Promotion Focus}

When it comes to startup firms-the target of this study, promotion focus can be identified based on two categories: CEOs and sales managers. First, promotion focus of CEOs can influence the implementation of sales strategies in the context of startup firms. In particular, when CEOs, in establishing startup firm's sales strategies, have a promotion focus, they try more creatively and actively to establish strategies related to attracting new customers, providing customer solutions, providing value, product differentiation, pricing, promotion, and loyalty enhancement (Higgins, 1989; Henker, Sonnentag, \& Unger, 2015). Such a motive will be more evident when CEOs know their customers well since the abovementioned diverse sales strategies cannot be established without knowledge about customers (Mohammadzadeh, Torbati, Asadi, \& Razavi, 2016). In other words, when CEO's customer knowledge assets are plentiful and CEOs have promotion focus, effectiveness of sales strategies will improve even more. Therefore, the following hypothesis can be set.

H5: The positive influence of CEO's customer knowledge assets on the CEO's effectiveness of sales strategies will be greater as their promotion focus becomes stronger.

Next, promotion focus of sales managers can influence the implementation of sales strategies. Particularly, when sales managers who actually conduct sales activities have promotion focus, they pursue their goals related to sales, profits, delivery observance, customer satisfaction, and discovery of new customers more creatively and actively (Higgins, 1989; Kim \& Heo, 2016). This motive is even clearer when sales managers have substantial knowledge regarding products or technology (Tiwana, 2008). In other words, when sales manager's product knowledge assets are sufficient and they have promotion focus, efficiency of sales activities shows greater improvement. Thus, the following hypothesis can be established.

H6: The positive influence of sales manager's technology knowledge assets on the sales manager's efficiency of sales activities will be greater as their promotion focus becomes stronger.

The following research model has been constructed based on the established hypotheses of this study. 


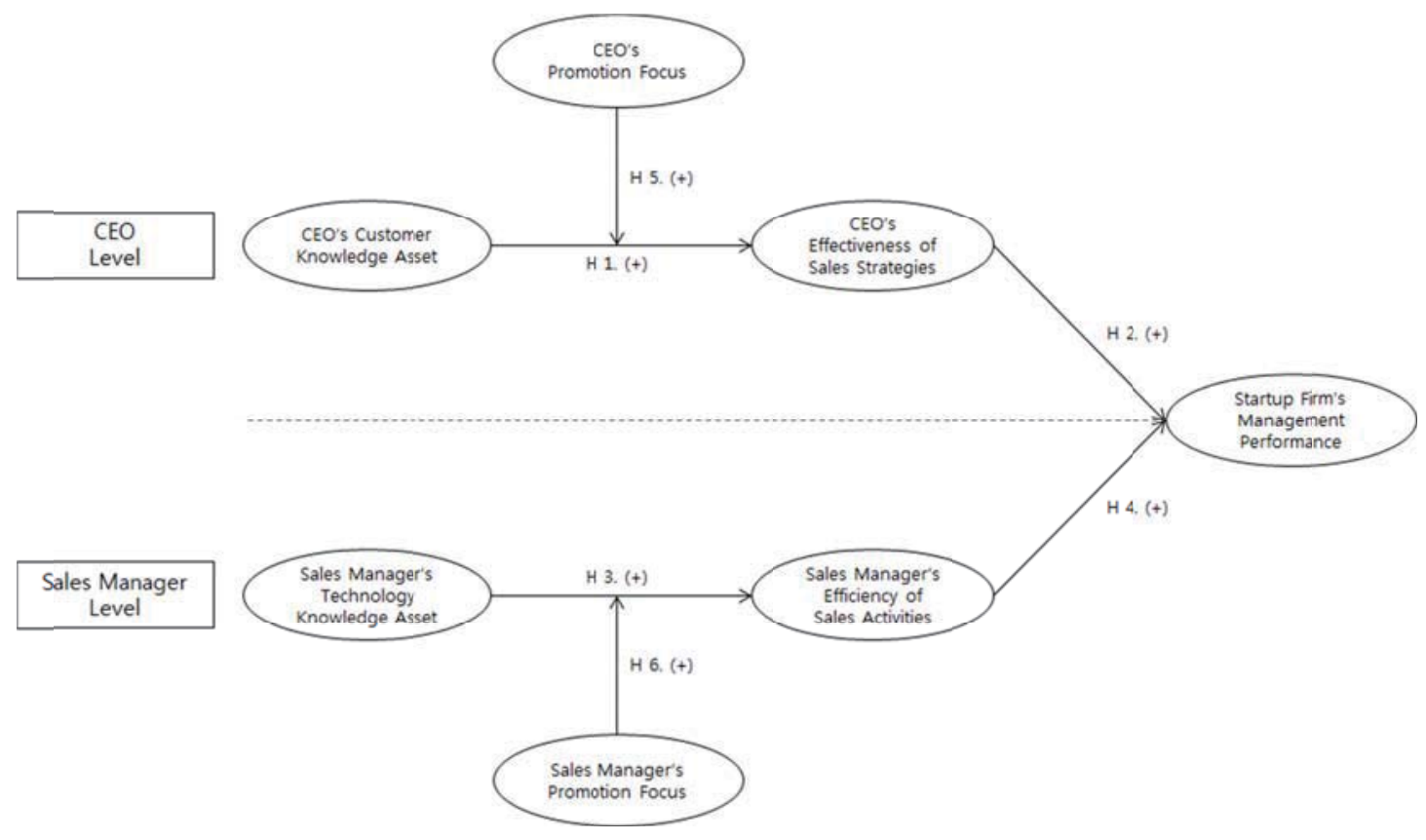

Figure 1: Research model

\section{Research Methodology}

\subsection{Data Collection}

This study deals with CEO's customer knowledge assets, sales manager's technology knowledge assets, promotion focus of CEOs and sales managers, CEO's effectiveness of sales strategies, sales manager's efficiency of sales activities, and startup firm's management performance. Accordingly, this study conducted questionnaire surveys targeting startup firms in Korea. While the existing knowledge asset-related studies have limitations in interpreting their research outcomes as they conducted measurements only on a certain aspect, this study employed dyadic measurement. That is, startup firm's CEOs and sales managers were grouped as one pair and questionnaire surveys targeted both of them. The questionnaire surveys were conducted at the Gyeongnam Technopark and the KAIST Technology Business Incubation Center and targeted firms established within these locations. The questionnaires were sent through mail, and follow-up emails were sent after asking for cooperation in advance over the phone. Out of 186 startup firms, 108 firms were surveyed, and the collection rate was $58.1 \%$.

\subsection{Measurement of Variables}

This study measured variables using scales that were used in the existing studies, which assured reliability and validity. First, for knowledge assets, the customer knowledge asset was measured with four items based on the research by Bontis (2001) and Trejo, Gutierrez, and Guzman (2016), while the technology knowledge asset was measured using four items based on the research by Mariadoss, Milewicz, Lee, and Sahaym (2014). Next, CEO's effectiveness of sales strategies and efficiency of sales activities were measured with four items and three items, respectively, after revising the measurement tool by Tiwana (2008). Next, management performance was measured with five items after revising the measurement tool by Kim and Jeon (2015). Lastly, CEOs and sales manager's promotion focus was measured with five items based on the study by Das and Kumar (2011).

Unlike existing studies, this study conducted dyadic measurement. For this purpose, the measurement variables were divided into CEO and sales manager of startup firm. In detail, CEO's customer knowledge asset, promotion focus, and effectiveness of sales strategies were measured by sales managers while sales manager's technology knowledge asset, promotion focus, efficiency of sales activities, and startup firm's management performance were measured by CEOs. All measurement items were measured on a 7-point Likert scale. Specific contents are provided in the appendix. 


\section{Data Analysis and Result}

\subsection{Subject Characteristics}

When it came to the characteristics of the firms that took part in the survey, the distribution ratios of respective industries were electricity and electronics (28.3\%), machinery and metal $(26.4 \%)$, software $(14.2 \%)$, and information and communications $(9.4 \%)$. When it came to the university major of the founders, $71.8 \%$ had studied engineering and $12.6 \%$ had majored in business administration or economics. When it came to educational background of

the founders at the time of establishing their firms, $52.9 \%$ had graduated from college, $26.5 \%$ had completed their master's degree, 9.8\% had completed their Ph.D., and $10.8 \%$ had graduated from high school. The correspondence rate of current CEO and founder was $89.6 \%$; most surveyed firms responded that the founder was responsible for management. When asked, in terms of company life cycle, in which of five stages-genesis, growth, hypergrowth, maturity, and decline-the firm was currently in, $60 \%$ responded that the firm was at the growth stage, $15.2 \%$ at the genesis stage, $11.4 \%$ at the hypergrowth stage, and 13.3 percent at the stage of maturity and higher. The average business career of the surveyed startup firms was approximately 9.62 years, average sales in the past three years was 3.18 billion won, and average number of employees was 14.9 .

\subsection{Reliability and Validity}

In order to examine the reliability and validity of the measurement tool, factor loading, Cronbach's alpha, composition reliability, average variance extracted (AVE), and correlation coefficient were reviewed using confirmatory factor analysis (CFA). According to the confirmatory factor analysis, goodness-of-fit index (GFI) was 0.864 , which was lower than the adequate level (0.9) but higher than the average level (0.85) and RMSEA was 0.031, indicating goodness of fit, since it was lower than the standard level (0.05). Since the chi-squared statistic is $168.9(\mathrm{df}=160, p$ $>$.194), indicating a significance probability of more than 0.05 , the covariance matrix reproduced by the inserted covariance matrix and measurement model appeared to be appropriate, without significant differences.

Cronbach- $\alpha$ values, assessing reliability, exceeded 0.7 (the standard level) and composite reliability (CR) was 0.9 and higher, showing high reliability. Average variance extracted (AVE), assessing validity, was 0.5 and higher (the standard level). On comparing the correlation coefficient between variables and square root values of average variance extracted, discriminant validity was found to exist since the correlation coefficients between factors were higher than the square root value of average variance extracted. Therefore, all measurement items of this study satisfied reliability and validity.

Table 2: Result of the reliability and validity test

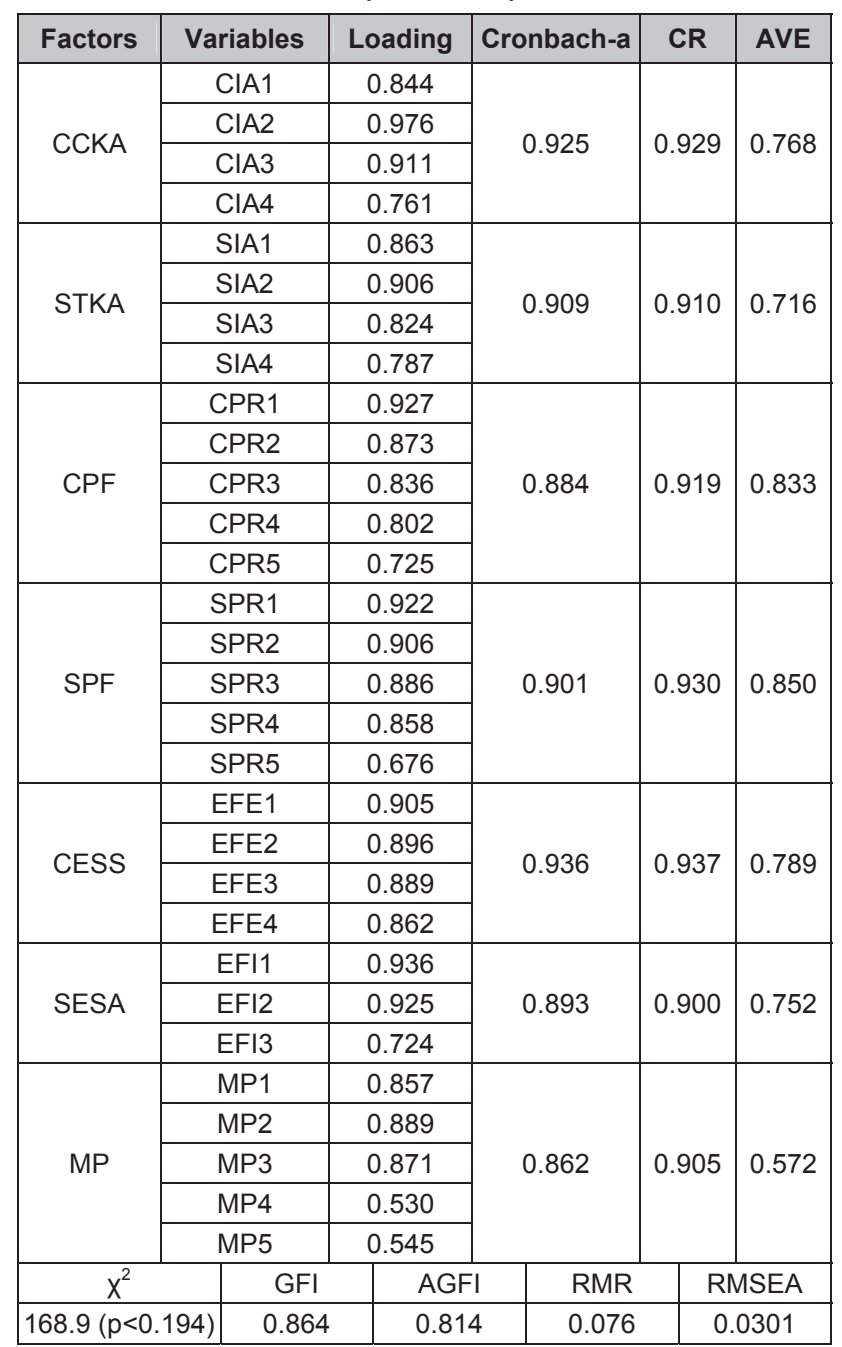

Note:

CCKA: CEO's Customer Knowledge Asset;

STKA: Sales Manager's Technology Knowledge Asset;

CPF: CEO's Promotion Focus:

SPF: Sales Manager's Promotion Focus;

CESS: CEO's Effectiveness of Sales Strategies;

SESA: Sales Manager's Efficiency of Sales Activities;

MP: Startup Firm's Management Performance. 
Table 3: Correlation and AVE

\begin{tabular}{|c|c|c|c|c|c|}
\hline & CCKA & STKA & CESS & SESA & MP \\
\hline CCKA & 0.876 & & & & \\
\hline STKA & 0.182 & 0.846 & & & \\
\hline CESS & 0.556 & 0.164 & 0.888 & & \\
\hline SESA & 0.230 & 0.256 & 0.347 & 0.867 & \\
\hline MP & 0.288 & 0.278 & 0.343 & 0.731 & 0.756 \\
\hline
\end{tabular}

Note:

CCKA: CEO's Customer Knowledge Asset;

STKA: Sales Manager's Technology Knowledge Asset;

CESS: CEO's Effectiveness of Sales Strategies;

SESA: Sales Manager's Efficiency of Sales Activities; MP: Startup Firm's Management Performance.

Diagonal matrix is the square root value of average variance extracted $(\sqrt{A V E})$.

\subsection{Hypotheses Test}

In order to verify the hypotheses of this study, empirical analysis was conducted using structural equation modeling. When taking into account the goodness-of-fit of the structural equation modeling, since chi-squared statistic is $189.9(\mathrm{df}=165)$ and significance probability is 0.053 , higher than the 0.05 significance level, the input covariance matrix and the covariance matrix reproduced by the research model corresponded to each other. This means that the research model is appropriate and explains input data well. However, since the chi-squared statistic is influenced by degrees of freedom, other goodness-of-fit indices have to be taken into consideration. Since GFI-the overall goodnessof-fit index-was 0.849 (lower than the standard 0.9), it can be accommodated. Since root mean square residual (RMSR) was 0.109 , which exceeded the standard 0.05 , but root mean square error average (RMSEA) was 0.048 , lower than the standard 0.05, the error could be deemed small. Therefore, when taking into account the chi-square statistic, GFI, and RMSEA, the goodness-of-fit of the overall research model is not excellent but is acceptable.

When respective path coefficients are examined for the verification of the study hypotheses, first, CEO's customer knowledge asset had a significant positive influence on CEO's effectiveness of sales strategies $(\beta=.609, t=5.854)$. In other words, sales strategies can be implemented effectively when CEOs are well aware of customers and business standards and procedures related to customers. Thus, Hypothesis 1 was supported.

Second, CEO's effectiveness of sales strategies has been found to enhance startup firm's management performance $(\beta=.223, t=2.543)$. In other words, the efforts and the strategic development designed for providing high value to customers are effective and the startup firm's management performance, considering the effort to improve satisfaction and loyalty to be genuine, was high. Thus, Hypothesis 2 was supported.

Third, sales manager's technology knowledge asset has been found to enhance sales manager's efficiency of sales activities $(\beta=.618, t=3.111)$. When sales managers are well aware of the technology related to firms' products and have enough knowledge to offer information well, efficiency of sales activities increases. This means that startup firms can carry out sales activities more smoothly when sales managers not only have information about customers but also vast technology knowledge. Thus, Hypothesis 3 was supported.

Fourth, sales manager's efficiency of sales activities $\beta=.625, t=7.47$ ) has been found to enhance startup firm's management performance. Thus, Hypothesis 4 was also supported.

Table 4: Hypotheses test results

\begin{tabular}{|c|c|c|c|c|c|c|c|}
\hline & IV & DV & \begin{tabular}{c|} 
Unstd. \\
Coefficient
\end{tabular} & $\begin{array}{l}\text { Std. } \\
\text { Error }\end{array}$ & \begin{tabular}{c|} 
Std. \\
Coefficient
\end{tabular} & $\begin{array}{c}\mathrm{t}- \\
\text { value }\end{array}$ & \begin{tabular}{|c|}
$p-$ \\
value
\end{tabular} \\
\hline $\mathrm{H} 1$ & CCKA & CESS & 0.609 & 0.104 & 0.537 & 5.854 & 0.000 \\
\hline $\mathrm{H} 2$ & CESS & MP & 0.223 & 0.088 & 0.201 & 2.543 & 0.006 \\
\hline H3 & STKA & SESA & 0.618 & 0.199 & 0.328 & 3.111 & 0.001 \\
\hline $\mathrm{H} 4$ & SESA & MP & 0.625 & 0.084 & 0.747 & 7.470 & 0.000 \\
\hline \multicolumn{3}{|c|}{$x^{2}$} & GFI & AGFI & RMR & \multicolumn{2}{|c|}{ RMSEA } \\
\hline \multicolumn{3}{|c|}{$189.9(p=0.053)$} & 0.849 & 0.802 & 0.109 & \multicolumn{2}{|c|}{0.0418} \\
\hline
\end{tabular}

In order to examine the moderating effect of CEO's and sales manager's promotion focus proposed in Hypotheses 5 and 6 , based on respective average values (CEO's promotion focus: 5.8 , sales manager's promotion focus: 5.54) of CEO's promotion focus and sales manager's promotion focus, the study subjects were divided into four groups: CEOs with high promotion focus (CPF_H), CEOs with low promotion focus (CFP_L), sales managers with high promotion focus (SPF_H), and sales managers with low promotion focus (SPF_L). Furthermore, based on the average value of CEO's customer knowledge assets $(M=5.78)$, they were divided into two groups: CEOs with high customer knowledge (CCKA_H) and CEOs with low customer knowledge (CCKA_L). Also, based on the average value of sales manager's technology knowledge assets $(M=5.87)$, they were divided into two groups: sales managers with high technology knowledge (STKA_H) and sales managers with low technology knowledge (STKA_L).

In order to verify Hypothesis 5, two-way ANOVA was conducted setting CEO's customer knowledge asset and CEO's promotion focus as fixed factors and setting CEO's 
effectiveness of sales strategies as the dependent variable. The main effect of the respective factors was found to be significant at a level of 0.05 . That is, as CEO's customer knowledge asset increased, CEO's effectiveness of sales strategies rose higher $(\mathrm{F}=10.52, \mathrm{p}<.002)$ and as CEO's promotion focus increased, CEO's effectiveness of sales strategies rose higher $(F=8.19, p<.005)$. The interaction effect, reflecting the moderating effect, was found to be significant at $0.1(F=2.95, p<.089)$. As shown in <Figure 2>, when CEO's promotion focus is low, there is not much difference whether CEO's customer knowledge asset level is high or not. However, when CEO's promotion focus is high, effectiveness can vary greatly based on CEO's customer knowledge asset level. Therefore, Hypothesis 5 was significantly supported at 0.1 .

Table 5: Moderating effect of CEO's promotion focus on CEO's customer knowledge asset

\begin{tabular}{|c|c|c|c|c|c|}
\hline Source & $\begin{array}{c}\text { Sum of } \\
\text { Squares }\end{array}$ & df & $\begin{array}{c}\text { Mean } \\
\text { Square }\end{array}$ & F & $\begin{array}{c}\mathbf{p}- \\
\text { value }\end{array}$ \\
\hline Intercept & 1556.110 & 1 & 1556.110 & 2257.45 & 0.000 \\
\hline CCKA_HL & 7.252 & 1 & 7.252 & 10.52 & 0.002 \\
\hline CPF_HL & 5.649 & 1 & 5.649 & 8.19 & 0.005 \\
\hline $\begin{array}{c}\text { CCKA_HL } \\
\text { *CPF_HL }\end{array}$ & 2.034 & 1 & 2.034 & 2.95 & 0.089 \\
\hline Error & 62.728 & 91 & 0.689 & & \\
\hline Total & 2523.324 & 95 & & & \\
\hline
\end{tabular}

Note: $\mathrm{R}$ Squared $=.337$ (Adjusted R Squared $=.315$ )

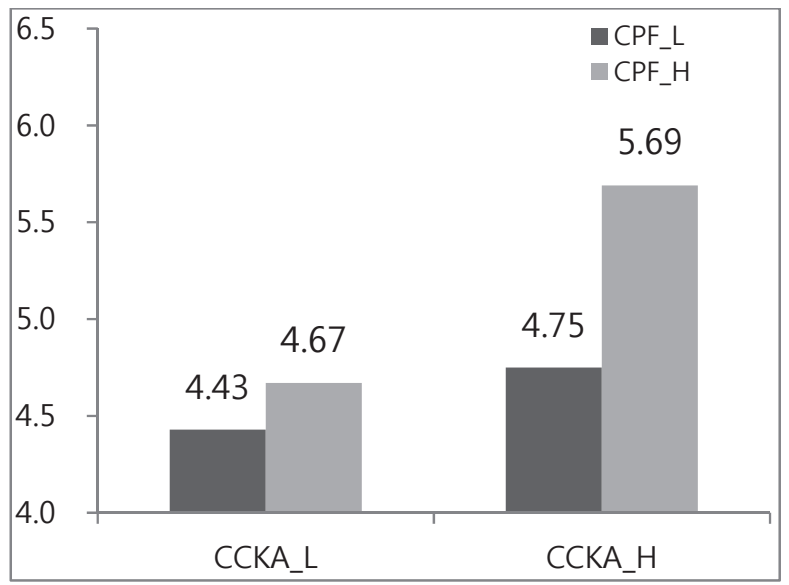

Figure 2: Moderating effect of CEO's promotion focus

Hypothesis 6 was tested in a similar way to Hypothesis 5. Two-way ANOVA was conducted after setting the sales manager's technology knowledge asset and promotion focus as fixed factors and setting sales manager's efficiency of sales activities as the dependent variable. The main effect of sales manager's technology knowledge asset was significant at 0.1 . In other words, as sales manager's technology knowledge asset level rose higher, sales manager's efficiency of sales activities increased ( $F=2.90$, $p<$.092). In addition, as sales manager's promotion focus rose higher, sales manager's efficiency of sales activities increased $(F=4.75, p<.032)$. The interaction effect, reflecting the moderating effect, was not significant $(F=0.04$, $p<.835)$. Therefore, Hypothesis 6 was rejected.

Table 6: Moderating effect of sales manager's promotion focus on sales manager's technology knowledge asset

\begin{tabular}{|c|c|c|c|c|c|}
\hline Source & $\begin{array}{c}\text { Sum of } \\
\text { Squares }\end{array}$ & df & $\begin{array}{c}\text { Mean } \\
\text { Square }\end{array}$ & F & p-value \\
\hline Intercept & 1495.740 & 1 & 495.740 & 975.49 & 0.000 \\
\hline STKA_HL & 4.441 & 1 & 4.441 & 2.90 & 0.092 \\
\hline SPF_HL & 7.289 & 1 & 7.289 & 4.75 & 0.032 \\
\hline $\begin{array}{c}\text { STKA_HL } \\
\text { * SPF_HL }\end{array}$ & 0.066 & 1 & 0.066 & 0.04 & 0.835 \\
\hline Error & 154.866 & 101 & 1.533 & & \\
\hline Total & 2003.604 & 105 & & & \\
\hline
\end{tabular}

Note: $\mathrm{R}$ Squared $=.105$ (Adjusted R Squared $=.078$ )

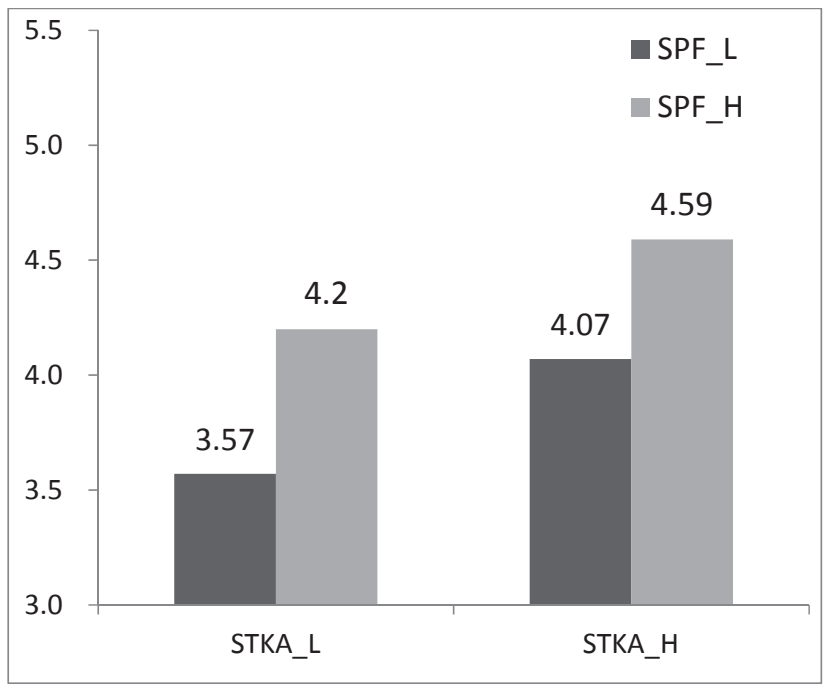

Figure 3: Moderating effect of sales manager's promotion focus

\section{Conclusion}

\subsection{Summary and Implications}

Nowadays, corporate knowledge assets are being perceived as an important determinant of corporate values, and enterprises are making significant efforts to develop and protect knowledge assets. However, most studies on knowledge assets are focused on large companies and small and medium-sized enterprises, and a detailed and 
empirical approach for small startup firms is lacking. In this light, this study aimed to examine the effects of knowledge assets of corporate management performance by targeting startup firms, which rely on these intangible assets. This study categorized startup firm's knowledge assets into customer knowledge asset and technology knowledge asset and examined the effects of knowledge assets on CEO's effectiveness of sales strategies and efficiency of sales activities and the effects on startup firm's management performance. In particular, this study examined the effects of the motivation to actively utilize knowledge assets on CEO's effectiveness of sales strategies and efficiency of sales activities. To this end, the study proposed a research model hypothesizing that promotion focus of CEO's and sales managers influences the relationship between knowledge assets and management performance, after introducing a motivational factor for promotion focus.

For the empirical analysis, dyadic questionnaire surveys were conducted targeting CEO's and sales managers of startup firms and hypotheses were tested using structural equation modeling. The analysis showed that CEO's customer knowledge asset enhanced CEO's effectiveness of sales strategies and sales manager's technology knowledge asset strengthened sales manager's efficiency of sales activities. Furthermore, effectiveness of sales strategies and efficiency of sales activities have been found to improve management performance of startup firms. Meanwhile, CEO's promotion focus strengthened effectiveness of sales strategies through the interaction with CEO's customer knowledge asset but there was no interaction effect between sales manager's promotion focus and technology knowledge asset.

This study provides the following practical implications. First, when it comes to startup firms, intangible assets such as customer knowledge asset and technology knowledge asset have positive influence on improvement of effectiveness and efficiency, which play a pivotal role in the enhancement of corporate management performance. Even in the case of technology-focused startup firms, CEO's and sales managers alike have to make efforts to secure and understand knowledge related to customers. Moreover, when it comes to sales managers, not only customer management but also understanding of technology and securement of knowledge take place, efficiency of sales activities increases. Second, CEO's promotion focus enhances the utilization effect of customer knowledge assets. When CEO's actively embrace new concepts, actively respond to the market, communicate with others, and are willing to take management risks, customer knowledge assets improve effectiveness of sales strategies. On the other hand, in comparison with sales manager's promotion focus not having significant results, CEO's motivation factor plays a more important role than employees' motivation factor. Third, since effectiveness of sales strategies and efficiency of sales activities had a positive influence on startup firm's management performance, when it comes to corporate management, securement of effectiveness and efficiency is also an important business management factor.

This study distinguishes itself from previous studies as follows: First of all, this study is distinct in the sense that it looked into the effects of knowledge assets on management performance in small technology-centered startup firms. Also, this study suggested the importance of CEO's promotion motive to corporate management performance by introducing the motive factor (promotion focus vs. prevention focus), which had been addressed mainly in consumer behavior studies, to the analysis of startup firm's knowledge asset utilization. Lastly, this study conducted assessments from a relatively objective viewpoint by incorporating evaluations of respondents to the dyadic questionnaire survey. That is, this study reflected realistic perceptions between members by having startup firm's CEOs assess sales managers and vice versa.

\subsection{Limitations and Future Studies}

This study has the following limitations. Since the study subjects were 108 firms, it has the limitation of having been unable to reflect the diverse characteristics of various industries. If a list of startup firms can be secured, sampling and research can be conducted in more systematic ways. However, studies on enterprises demand vast research expenses and have time constraints.

Second, the moderating effect of prevention focus was not examined. This study regarded promotion focus as much more important than prevention focus, which tries to avoid potential losses, since startup firms have a high risktaking tendency in pursuing potential benefits based on new products or ideas. However, since the effect of moderating focus can differ based on the scale of firm, type of business, and market situation, prevention focus should be examined as well.

Third, this study does not reflect external and internal business environments. The surveyed firms have different business environments and conditions. Especially, when it comes to corporate decision-making, various environmental elements including ordinary environment surrounding firms, work environment, and internal environment exert influence. However, given the aforementioned elements, external validity would need to be further tested. The criteria used to reflect external and internal business environments need to be applied to measurement and analysis. 


\section{References}

Apostolou, D., Mentzas, G., Abecker, A., Maas, W., Georgolios, P., \& Kafentzis, K. (2005). Challenges and directions in knowledge asset trading. International Journal of Intelligent Systems in Accounting, Finance \& Management, 13(1), 1-15.

Atuahene-Gima, K., \& Murray, J. Y. (2004). Antecedents and outcomes of marketing strategy comprehensiveness. Journal of Marketing, 68(4), 33-46.

Bettman, J. R. (1988). Processes of adaptivity in decision making. In Michael Houston, Advances in consumer research, Volume 15 (pp.1-4). Cambridge, MA: Association for Consumer Research.

Bitner, M. J., Booms, B. H., \& Mohr, L. A. (1994). Critical service encounters: The employee's viewpoint. Journal of Marketing, 58(4), 95-106.

Blank, S., \& Dorf, B. (2012). The startup owner's manual: The step-by-step guide for building a great company. Pennsauken, NJ: BookBaby.

Boles, J. S., Johnson, J. T., \& Barksdale, H. C. Jr. (2000). How salespeople build quality relationships: A replication and extension. Journal of Business Research, 48(1), 75-81.

Bonoma, T. V. (1988). Marketing performance assessment. Boston, MA: Harvard Business School Press.

Bontis, N. (2001). Assessing knowledge assets: A review of the models used to measure intellectual capital. International Journal of Management Reviews, 3(1), 41-60.

Brockner, J., Higgins, E. T., \& Low, M. B. (2004). Regulatory focus theory and the entrepreneurial process. Journal of Business Venturing, 19(2), 203-220.

Cavusgil, S. T., \& Zou, S. (1994). Marketing strategyperformance relationship: An investigation of the empirical link in export market ventures. Journal of Marketing, 58(1), $1-21$.

Centobelli, P., Cerchione, R., \& Esposito, E. (2017). Knowledge management in startups: Systematic literature review and future research agenda. Sustainability, 9(3), 361.

Cerchione, R., \& Esposito, E. (2017). Using knowledge management systems: A taxonomy of SME strategies. International Journal of Information Management, 37(1), 1551-1562.

Clark, B. H. (2000). Managerial perceptions of marketing performance: Efficiency, adaptability, effectiveness and satisfaction. Journal of Strategic Marketing, 8(1), 3-25.

Das, T. K., \& Kumar, R. (2011). Regulatory focus and opportunism in the alliance development process. Journal of Management, 37(3), 682-708.

Fidel, P., Schlesinger, W., \& Cervera, A. (2015). Collaborating to innovate: Effects on customer knowledge management and performance. Journal of Business Research, 68(7), 1426-1428.
Grönroos, C., \& Ojasalo, K. (2004). Service productivity: Towards a conceptualization of the transformation of inputs into economic results in services. Journal of Business Research, 57(4), 414-423.

Han, S. S. (2016). Industry structure, technology characteristics, technology marketing and performance of technology-based start-ups: With focus on technology marketing strategy. Journal of Distribution Science, 14(2), 93-101.

Henker, N., Sonnentag, S., \& Unger, D. (2015). Transformational leadership and employee creativity: The mediating role of promotion focus and creative process engagement. Journal of Business and Psychology, 30(2), 235-247.

Higgins, E. T. (1989). Self-discrepancy theory: What patterns of self-beliefs cause people to suffer. Advances in Experimental Social Psychology, 22, 93-136.

Higgins, E. T. (1997). Beyond pleasure and pain. American Psychologist, 52(12), 1280-1300.

Higgins, E. T. (2000). Making a good decision: Value from fit. American Psychologist, 55(11), 1217-1230.

Homburg, C., Müller, M., \& Klarmann, M. (2011). When does salespeople's customer orientation lead to customer loyalty? The differential effects of relational and functional customer orientation. Journal of the Academy of Marketing Science, 39(6), 795-812.

Kaiser, D. B., Köhler, T., \& Weith, T. (2016). Knowledge management in sustainability research projects: Concepts, effective models, and examples in a multi-stakeholder environment. Applied Environmental Education \& Communication, 15(1), 4-17.

Kim, D. E., \& Jeon, I. O. (2015). Effects of the founder's abilities of the business incubator center to the performance of the resident enterprises: Focusing on the characteristics of the operating types and the manager capabilities. Korean Corporation Management Review, 64, 71-85.

Kim, S. D., \& Heo, S. (2015). The effects of governancemotivation fit on sales managers' performance of start-up company. Korean Management Review, 45(1), 95-119.

Krohmer, H., Homburg, C., \& Workman, J. P. (2002). Should marketing be cross-functional? Conceptual development and international empirical evidence. Journal of Business Research, 55(6), 451-465.

Lee, B. K. S., Oh, S., \& Kim, S. D. (2014). The effects of goal incongruity between franchisor and franchisee on regulatory focus, performance, and opportunism of franchisee. Journal of Distribution Science, 12(2), 39-47.

Lee, C., \& Griffith, D. A. (2004). The marketing strategyperformance relationship in an export-driven developing economy: A Korean illustration. International Marketing Review, 21(3), 321-334. 
Lee, H. (2017). The differential factors influencing online \& mobile shopping behavior. Journal of Distribution Science, 15(9) 27-36.

Lopes, C. M., Scavarda, A., Hofmeister, L. F., Thomé, A. M. T., \& Vaccaro, G. L. R. (2017). An analysis of the interplay between organizational sustainability, knowledge management, and open innovation. Journal of Cleaner Production, 142, 476-488.

Mariadoss, B. J., Milewicz, C., Lee, S., \& Sahaym, A. (2014). Salesperson competitive intelligence and performance: The role of product knowledge and sales force automation usage. Industrial Marketing Management, 43(1), 136-145.

Mathew, A. O., Rodrigues, L. L., \& Vittaleswar, A. (2012). Human factors \& knowledge management: A system dynamics based analysis. Journal of Knowledge Management Practice, 13(2), 241-247.

McQuiston, D. H. (1989). Novelty, complexity, and importance as causal determinants of industrial buyer behavior. Journal of Marketing, 53(2) 66-79.

Menon, A., Bharadwaj, S. G., Adidam, P. T., \& Edison, S. W. (1999). Antecedents and consequences of marketing strategy making: a model and a test. Journal of Marketing, 63(2), 18-40.

Mohammadzadeh, F., Torbati, E., Asadi, R., \& Razavi, K. (2016) Enhancing sales performance through customer knowledge management. International Journal of Economics, Commerce and Management, 4(12), 746-761.

Mouzas, S. (2006). Efficiency versus effectiveness in business networks. Journal of Business Research, 59(1011), 1124-1132.

Park, E. Y., \& Lee, E. Y. (2016). The effect of color on perceived price attractiveness: Interaction of regulatory focus and involvement. Journal of Distribution Science, 14(10) 117-1267.

Pérez-Nordtvedt, L., Kedia, B. L., Datta, D. K., \& Rasheed, A. A. (2008). Effectiveness and efficiency of cross-border knowledge transfer: An empirical examination. Journal of Management Studies, 45(4), 714-744.

Pollard, D., \& Jemicz, M. (2006). The internationalisation of Czech SMEs: Some issues relating to marketing knowledge deficiencies. International Journal of Entrepreneurship and Small Business, 3(3-4), 400-416.

Porter, M. E. (1980). Competitive strategy. New York, NY: Free Press.

Simon, H. A. (1965). Administrative behavior: A study of decision-making process in administrative organization. New York, NY: Free Press.

Spender, J. C. (1996). Making knowledge the basis of a dynamic theory of the firm. Strategic Management Journal, 17(S2), 45-62.

Spiro, R. L., \& Weitz, B. A. (1990). Adaptive selling: Conceptualization, measurement, and nomological validity. Journal of Marketing Research, 27(1), 61-69.
Sujatha, R., \& Krishnaveni, R. (2015). Knowledge management: An ingredient for sustainability of organizations. International Business Management, 9(3), 299-309.

Thomas, L., Ambrosini, V., \& Hughes, P. (2017). The role of organizational citizenship behaviour and rewards in strategy effectiveness. The International Journal of Human Resource Management, Published Online, 1-30.

Thompson, D. V., Hamilton, R. W., \& Rust, R. T. (2005). Feature fatigue: When product capabilities become too much of a good thing. Journal of Marketing Research, 42(4), 431-442.

Tiwana, A. (2009). Governance-knowledge fit in systems development projects. Information Systems Research, 20(2), 180-197.

Tortosa, V., Moliner, M. A., \& Sánchez, J. (2009). Internal market orientation and its influence on organisational performance. European Journal of Marketing, 43(11/12), 1435-1456.

Trejo, J. M., Gutiérrez, J. S., \& Guzman, G. M. (2016). The customer knowledge management and innovation. Contaduría y Administración, 61(3), 456-477.

Van der Wal, R. W. E. (2017). Knowledge and knowledge assets: Employees perception. International Journal of Contemporary Research and Review, 8(5), 20123-20128.

Wadhwa, P., McCormick, M., \& Musteen, M. (2017). Technological innovation among internationality active SMEs in the Czech economy: Role of human and social capital of CEO. European Business Review, 29(2), 164-180.

Walker Jr, O. C., \& Ruekert, R. W. (1987). Marketing's role in the implementation of business strategies: a critical review and conceptual framework. Journal of Marketing, 51(3), 15-33.

Wang, H., Zhao, S., \& Chen, G. (2017). Firm-specific knowledge assets and employment arrangements: Evidence from CEO compensation design and CEO dismissal. Strategic Management Journal, 38(9), 1875-1894.

Wang, M. H., \& Yang, T. Y. (2016). Investigating the success of knowledge management: An empirical study of small-and medium-sized enterprises. Asia Pacific Management Review, 21(2), 79-91.

Yoo, C., \& Hyun, S. (2011). Comparative analyses on the effects of tensile price discounts by discount size and regulatory focus. Journal of Consumer Studies, 22(2), 253-275.

Zablah, A. R., Chonko, L. B., Bettencourt, L. A., Allen, G., \& Haas, A. (2012). A job demands-resources (JD-R) perspective on new product selling: A framework for future research. Journal of Personal Selling \& Sales Management, 32(1), 73-87. 


\section{Appendix}

\section{CEO's Customer Knowledge Asset ( $\alpha=.925)$}

1. CEO is well aware of buyers.

2. CEO is well aware of the business standards with buyers.

3. CEO is well aware of the business procedures with buyers.

4. CEO is well aware of strategies necessary for effective sale.

Sales Manager's Technology Knowledge Asset ( $\alpha=.909)$

1. Sales manager is well aware of the functions and characteristics of company products.

2. Sales manager is well-informed of the technological aspects of company products.

3. Sales manager is well aware of the production process of company products.

4. Sales manager is well aware of the production schedule of company products.

\section{CEO's Promotion Focus ( $\alpha=.884)$}

1. CEO actively embraces new business ideas.

2. CEO wishes to preoccupy the market by swift movement.

3. CEO wishes to improve performance by sharing diverse business-related information with others.

4. CEO actively responds to business environment changes.

5. CEO takes risks to accomplish goals.

Sales Manager's Promotion Focus ( $\alpha=.901)$

1. Sales manager actively embraces new business ideas.

2. Sales manager wishes to preoccupy the market by moving swiftly.
3. Sales manager wishes to improve performance by sharing diverse business-related information with others.

4. Sales manager actively responds to business environment changes.

5. Sales manager takes risks to accomplish goals.

\section{CEO's Effectiveness of Sales Strategies $(\alpha=.936)$}

[Do you think your company's business strategies in the last six months were effective?]

1. New buyer development strategy

2. Strategy to provide optimal value to buyer

3. Marketing and promotion strategy

4. Buyer satisfaction and loyalty improvement strategy

Efficiency of Sales Manager's Sales Activities ( $\alpha=.893$ ) [Do you think your company's business activities in the last six months were efficient?]

1. Sales volume

2. Price policy and margin

3. Discovering new trade partners

\section{Management Performance $(\alpha=.862)$}

[How was your company's performance in the past three years in comparison with competitors?]

1. Market dominance satisfaction

2. Sales satisfaction

3. Profitability satisfaction

4. Customer satisfaction

5. Commercialization/Product development time satisfaction 